\title{
is Research Square \\ Functionally Calibrating Life Satisfaction: The Case of Mating Motives and Self-Perceived Mate Value
}

\author{
Ahra Ko ( $\nabla$ ahrako@asu.edu ) \\ Arizona State University https://orcid.org/0000-0002-7295-1097 \\ Eunkook M. Suh \\ Yonsei University \\ Ji-eun Shin \\ Chonnam National University \\ Steven Neuberg \\ Arizona State University
}

\section{Research Article}

Keywords: life satisfaction, mate value, mating motivation, functional approach

Posted Date: October 8th, 2021

DOI: https://doi.org/10.21203/rs.3.rs-947875/v1

License: @ (i) This work is licensed under a Creative Commons Attribution 4.0 International License.

Read Full License 


\section{Abstract}

If life satisfaction has functional significance for goal achievement, it should be calibrated to cues of potential success on active and fundamentally important goals. Within the context of mating motivation, we tested this hypothesis with self-perceived mate value-an assessment of one's potential mating success. As hypothesized, because most individuals (eventually) seek long-term relationships, selfperceived long-term mate value predicted life satisfaction for men and women regardless of relationship status. In contrast, and also as hypothesized, self-perceived short-term mate value predicted life satisfaction only for individuals with short-term mating goals-single uncommitted men (Studies 1, 2A, and 2B), individuals dispositionally motivated toward short-term relationships (Studies 2A and 2B), and single uncommitted women for whom short-term mating motivation was experimentally engaged, enabling causal inference (Study 3). Results support a functional conceptualization of life satisfaction, showing that currently active mating goals can shape the extent to which goal-specific self-perceived mate value predicts life satisfaction.

\section{Introduction}

People frequently audit their life satisfaction. Why do people engage in this evaluation? Does life satisfaction serve important functions, or is it merely an end in itself?

We explore the view that life satisfaction, like other subjective affective and cognitive states, functions as part of a psychological system that monitors current and potential achievement on important goals. From this perspective, the phenomenology of life satisfaction provides a useful indicator of how well one is moving toward or meeting one's goals, thereby providing useful information for, and potentially motivating, subsequent desirable action. In fact, life satisfaction precedes many adaptive behaviors often leading to success (Luhmann et al., 2013; Lyubomirsky et al., 2005).

The aim of the current paper is to investigate the putative first stage of this functional process - whether currently active and important goals shape the extent to which life satisfaction is sensitively and selectively calibrated by goal-specific cues of success, especially for the goals that are fundamental to reproductive fitness (Kenrick et al., 2010; Neel et al., 2016). We focus in this research on mating motives and on cues people may use to assess their likely success in addressing them, because acquiring and retaining mates is of fundamental concern to nearly all people at some point in their lives and different strategies for successful mating enable nuanced hypotheses not readily derived by other conceptual approaches.

\section{A Functional Approach on Life Satisfaction}

Life satisfaction is a subjective, cognitive evaluation of one's life as a whole (Diener et al., 1985). Although the common view is that most people seek to maximize life satisfaction, from an evolutionary perspective humans are not designed to do so, per se. Rather, life satisfaction is likely one component of a behavioral regulation mechanism shaped by natural selection (Nesse, 1990). Like other inner 
experiential states that are of pervasive concern to people (e.g., self-esteem, self-regard, self-actualization, self-consistency; Kenrick et al., 2010; Leary, 2007; Leary et al., 1995; Mahadevan et al., 2018), life satisfaction can be viewed partially as functioning both to indicate one's success or failure on active, psychologically prominent goals and to facilitate further adaptive desirable behaviors. For instance, selfesteem is now widely viewed as an interpersonal monitor that gauges an individual's level of social acceptance and, thus, ultimately serves roles in regulating social inclusion (Kirkpatrick et al., 2002; Leary et al., 1995; Leary \& Baumeister, 2000). Such a psychological mechanism dedicated to tracking one's success or failure, aggregating broadly across fundamental social challenges and then facilitating functionally valuable actions, would be of great adaptive benefit.

Indeed, the experience of life satisfaction seems to be tied to movement towards important personal goals (Hofer \& Chasiotis, 2003; Schimmack et al., 2002; Schultheiss et al., 2008). For example, possessing greater resources predicts higher life satisfaction, but only to the extent that these resources help people achieve their goals (Carver \& Scheier, 1990; Diener \& Fujita, 1995). Moreover, when people succeed in domains unrelated to their active goals, they tend not to receive a boost in life satisfaction (Brunstein et al., 1998; Diener et al., 1995).

Some goals, on average, are more fundamental than others. As an ultra-social species (Richerson \& Boyd, 1998), humans have long had to solve many recurrent social challenges, such as evading physical harm, avoiding disease, making friends, attaining status, acquiring mates, retaining mates, and caring for family (Kenrick et al., 2010; Neel et al., 2016; Neuberg et al., 2010). Each fundamental social challenge engages qualitatively distinct motivational systems that employ cognitive, affective, and behavioral mechanism to identify and manage goal-specific opportunities and threats (Beall \& Tracy, 2017; Neuberg \& Schaller, 2015; Tracy, 2014). That is, different social challenges selectively activate different motivational systems, which in turn selectively process goal-specific cues and information toward enabling people to generate goal-facilitating outcomes (Barrett \& Kurzban, 2006). This conceptual approach implies that currently important and salient goals should selectively calibrate life satisfaction in response to goal-specific cues and information.

\section{Mating Goals and Life Satisfaction}

The acquisition and retention of mates is fundamental to survival and reproductive fitness. It is thus not surprising that establishing and maintaining a committed relationship predicts robust, long-lasting high life satisfaction (Diener et al., 2000; Luhmann et al., 2012). On the functional view, however, life satisfaction should be calibrated not only to actual mating success but also to cues suggesting whether one is likely, in the future, to succeed in acquiring and retaining mates.

One important cue to future mating success is mate value (Back et al., 2011; Bugental, 2000; Waynforth, 2001). Individuals with high mate value-who have qualities desired by potential romantic partners relative to mating competitors-are more likely to succeed (relative to those with lower mate value) in securing romantic partners of high mate value and in increasing reproductive success (Conroy-Beam et al., 2019; Gangestad \& Simpson, 2000). Although people desire partners of the highest possible mate 
value, most people in practice end up with partners similar to them in mate value (Conroy-Beam \& Buss, 2016; Luo \& Klohnen, 2005). This implies that people have a relatively accurate sense of both their own and others' mate value and, in turn, calibrate their mating aspirations, preferences, strategies, and efforts to their self-perceived mate value in ways to increase mating success (Buston \& Emlen, 2003; Maner \& Miller, 2014; Penke et al., 2007).

Because mate value has such significant implications for mating success, if life satisfaction has functional significance for goal achievement, we would expect people to calibrate their life satisfaction to their self-perceived mate value.

\section{The Significance of Mate Value for Life Satisfaction is likely to Vary by Mating Goal}

Mate value is a useful cue of future mating success and is thus likely to shape life satisfaction. However, there exist substantial individual differences in how frequently and strongly motivated people are to achieve mating goals and in how people seek to do so. Some of these differences are linked to one's mating strategy-for example, whether one is motivated to seek a long-term committed relationship versus a short-term uncommitted sexual opportunity. Individual's motivation for the specific mating strategy is partially shaped by features such as sex and relationship status.

Sex. Men and women confront somewhat different adaptive problems in short-term versus long-term mating relationships (Clark \& Hatfield, 1989; Gangestad \& Simpson, 2000; Oliver \& Hyde, 1993). Because offspring require from women a much higher minimal obligatory investment than from men (e.g., sexspecific costs associated with gestation, lactation), the potential reproductive costs of less selective short-term mating are much higher for women than for men (Trivers, 1972). Not only do women report that casual, low-investment sex is less desirable than do men, but women also report that they engage in short-term mating relationships less often than do men (Buss \& Schmitt, 1993; Haselton \& Buss, 2000; Schmitt, 2005; Schmitt et al., 2003).

In contrast, both men and women place similarly great importance in securing a committed long-term bond with a reliable and nurturant mate. This is likely because bonded long-term mates tend to provide substantial investments in their partners and offspring, thereby greatly enhancing reproductive fitness for both partners (Geary, 2000; Kaplan et al., 2000; Ko et al., 2020).

Relationship Status. As discussed, for individuals not in committed long-term relationships, short-term mating has different implications for men than for women.

For those in committed relationships, however, the benefits of short-term mating tend to be relatively low for most women and men, partially because the cost of losing a high-investment committed partner exceeds the potential benefit of having multiple low-investment sexual partners-even for men (ConroyBeam et al., 2015). Indeed, once people form long-term relationships, they generally allocate their resources away from seeking new mating partners and toward maintaining their existing relationship (Neel et al., 2016). 


\section{Overview of the Current Research}

Across four studies, we tested the general hypothesis that active mating goals are likely to shape the extent to which life satisfaction is calibrated to mate value, but in specific functional ways (Figure 1). Study 1 tested our basic predictions that features closely tied to long-versus short-term mating goals, such as sex and relationship status, predict the association between mate value and life satisfaction. Specifically, we hypothesized that self-perceived mate value as a long-term, committed partner positively predicts life satisfaction of both men and women regardless of their current relationship status, whereas self-perceived mate value as a short-term, casual-sex partner positively predicts life satisfaction of men, especially those not in committed relationships. In Studies 2A and 2B, we tested the hypothesis that individual differences in mating motivation directly shape the observed sex-and relationship-specific links between self-perceived mate value and life satisfaction. Specifically, we predicted that for those highly motivated toward short-term mating, self-perceived short-term mate value will positively predict life satisfaction. To test the causal link between mating goal and the significance of mate value for life satisfaction, Study 3 experimentally manipulated short-term mating motivation. If the specific patterns hypothesized of uncommitted men are due primarily to sex differences in short-term mating motivation, then uncommitted (but not committed) women who are experimentally motivated toward short-term mating should exhibit a pattern more similar to uncommitted men-a stronger positive association between self-perceived short-term mate value and life satisfaction. Finally, we conducted internal metaanalyses of our findings.

\section{Study 1}

In Study 1, we examined (a) whether people distinguish their mate value as long-term versus short-term mating partners-an assumption underlying our specific hypotheses-(b) the extent to which life satisfaction is differentially linked to long- versus short-term self-perceived mate value, and (c) whether this differentiation is predicted by people's sex and relationship status, as demographic markers of specific mating goals.

\section{Method}

Participants. We estimated a small effect size $\left(f^{2}=.02\right)$ for a three-way interaction and computed an $a$ priori required sample size of 725 participants using a two-tailed test, $a=.05$, and power $=.80$. We recruited participants from an introductory psychology subject pool at a large Southwestern university and analyzed data from 385 women $(M=19.1$ years, $S D=1.34)$ and 436 men $(M=19.5$ years, $S D=1.80)$ who self-reported as heterosexual[1] and completed the measures designed for the current study.

Materials and Procedure. All measures throughout were approved by the Institutional Review Board (IRB). Following prior research, we assessed two forms of self-perceived mate value by asking participants "Compared with other women [men] you know who are about your age, how desirable do men [women] 
find you as a long-term mate or marriage partner [a short-term mate or casual sex partner]?" (1 = Not at all desirable, 9 = Extremely desirable, Haselton, 2003). The order of the two questions was counter balanced.

To assess life satisfaction, we employed the Satisfaction With Life Scale (Diener et al., 1985), comprising five items asking respondents to rate their global life satisfaction from their subjective perspective (e.g., "I am satisfied with my life"; 1 = Strongly disagree, 7 = Strongly agree, $\mathrm{a}=.94$ ).

Relationship commitment was assessed via participants' current relationship status. Participants in a relationship with one person exclusively, engaged, or married were classified as being in a committed relationship $(n=275)$; those who were single or in an open relationship were classified as being in an uncommitted relationship $(n=546)$.

\section{Results}

Throughout, we contrast coded sex (- 0.5 for woman, 0.5 for man) and relationship status ( -0.5 for uncommitted, 0.5 for committed), centered mate values and life satisfaction (Cohen et al., 2003), and reported standardized coefficients $(\beta)$.

First, consistent with an underlying assumption that people differentiate their long-term and short-term mate value, there was only a small correlation between those two constructs, $r=.12, p<.001$.

Second, self-perceived long-term mate value predicted life satisfaction, $r=.27, p<.001$. As hypothesized, men and women who believe they are highly desirable as long-term mating partners reported higher life satisfaction regardless of their current relationship status (Table 1; Figure 2A).

Third, there was the hypothesized Sex 'Relationship Status ' Short-term Mate value three-way interaction on life satisfaction, $\beta=-.31,95 \% \mathrm{Cl}[-.59,-.03], t(813)=-2.14, p=.032, R^{2}=.06$ (Figure 2B). For uncommitted participants, there was the predicted significant Sex' Short-term Mate value two-way interaction, $\beta=.35,95 \% \mathrm{Cl}[.18, .51], t(542)=4.00, p<.001$, such that beliefs about one's desirability as a short-term mating partner positively predicted life satisfaction for uncommitted men but not for uncommitted women. For committed participants, however, this two-way interaction was nonsignificant, $\beta=.04, t(271)=0.32, p=.75$. Once committed to their relationships, short-term mate value predicted life satisfaction neither for committed men nor committed women (Table 1).

Table 1. Correlations between Self-perceived Mate value and Life Satisfaction 


\begin{tabular}{|c|c|c|c|c|c|c|}
\hline & \multicolumn{3}{|c|}{ Long-term mate value } & \multicolumn{3}{|c|}{ Short-term mate value } \\
\hline & Study 1 & Study $2 A$ & Study 2B & Study 1 & Study $2 A$ & Study $2 B$ \\
\hline Uncommitted men & $.22^{\star \star \star}$ & $.37^{\star \star \star}$ & $.65^{\star \star \star}$ & $.31^{\star \star \star}$ & $.41^{\star \star \star}$ & $.44^{\star \star *}$ \\
\hline Uncommitted women & $.29 * \star \star$ & $.30 \star \star$ & $.46^{\star \star \star}$ & -.03 & -.05 & .13 \\
\hline Committed men & $.34 * \star \star$ & $.28 * \star \star$ & $.31^{\star \star \star}$ & .08 & .02 & .03 \\
\hline Committed women & $.19 *$ & $.25^{\star \star \star}$ & $.32^{\star \star \star}$ & .04 & -.03 & .15 \\
\hline
\end{tabular}

$\star p<.05, * \star p<.01, * \star \star p<.001$

\section{Discussion}

This study provides preliminary support for our hypotheses. First, as evidenced by the small correlation between self-perceived long- and short-term mate value, and the differential utility of each for predicting life satisfaction, it seems clear that people view their long-term mate value and short-term mate value as at least somewhat distinct features.

More focal, people who believe themselves to be highly desirable as long-term mating partners were more satisfied with their lives, regardless of their sex and current relationship status. In contrast, short-term mate value predicted life satisfaction for single uncommitted men only. These findings comport with known sex and relationship differences in mating strategies (Buss \& Schmitt, 1993; Schmitt, 2005; Schmitt et al., 2003), and are consistent with the broader idea that self-perceived mate value is likely to be systematically linked to life satisfaction only to the extent it is relevant to achieving sex-and relationshipspecific mating goals.

[1] Across studies, we excluded non-heterosexual individuals prior to analyses; given our focus on differing benefits and costs of short- versus long-term relationships for male and female mating outcomes, we did not have specific a priori hypotheses for non-heterosexual individuals.

\section{Studies $2 a$ \& 2b}

Our approach hypothesizes that self-perceived short-term mate value predicts life satisfaction specifically for those for whom short-term mating is a desirable strategy-typically uncommitted men. To examine the proposed moderating effect of short-term mating motivation on the significance of self-perceived mate value for life satisfaction, these studies extended beyond demographic proxies for mating motivations (i.e., sex and relationship status) by directly assessing individual differences in short-term mating motivation.

These studies had three additional aims. First, we attempted to manipulate self-perceived short-term mate value to investigate the causal relationship between self-perceived short-term mate value and life satisfaction. Unable to find manipulations in the literature specifically designed to alter self-perceived 
short-term mate value, we modified methods designed to manipulate self-perceived 'general' mate value. Second, we began exploring how life satisfaction might link to functionally relevant behavior. If life satisfaction indicates one's prospects for success on one's goal, it should motivate relevant action to achieve that goal. Thus, we assessed self-reports of unrestricted sexual behavior to test the hypothesis that life satisfaction would statistically mediate the association between short-term mate value and short-term mating behavior. Last, we examined the robustness of our findings to rule out alternative explanations.

\section{Method}

Participants. We sought at least 150 participants per cell in a Sex' Relationship Status design. We collected data from Amazon's Mechanical Turk and analyzed the data from 290 women $(M=36.2$ years, $S D=11.4)$ and 383 men $(M=34.3$ years, $S D=10.6)$ for Study $2 A$ and 255 women $(M=35.8$ years, $S D=$ $10.15)$ and 329 men $(M=33.6$ years, $S D=9.37)$ for Study $2 B$ who self-reported as heterosexual and passed an attention check.

\section{Procedure and Materials.}

Pre-Manipulation Measure. To measure individual differences on short-term mating motivation, we asked participants to indicate agreement with the statement: "I am currently motivated to have a short-term (e.g., brief affair) or casual-sex relationship" (1 = Strongly disagree to 7 = Strongly agree; Hill et al., 2012).

Study 2A Manipulation by Implicit Social Comparison. Based on the hypothesis that implicit social comparison would alter people's assessment of their own mate value (Gutierres et al., 1999; Kenrick et al., 1994), and that physical attractiveness is closely tied to short-term mate value for both men and women (Li \& Kenrick, 2006), participants rated sexual desirability of photographs of (ostensibly) samesex local users of a popular dating app widely known for facilitating short-term mating. Participants randomly assigned to the high mate value condition $(n=340)$ rated the sexual desirability of 16 lowdesirable, 2 average-desirable, and 2 high-desirable same-sex photographs; participants assigned to the low mate value condition $(n=333)$ rated the sexual desirability of 16 high-desirable, 2 average-desirable, and 2 low-desirable same-sex photographs ( 1 = Not at all sexually undesirable, $9=$ Extremely sexually desirable).

Study 2B Manipulation by Direct Feedback. We employed and modified a method from previous research designed to manipulate self-perceived general mate value (Bailey et al., 2011; Bird et al., 2016; Surbey \& Brice, 2007). Within the context of ostensibly revising a fictitious personality inventory, participants completed a wide range of survey questions assessing physical appearance (e.g., height, weight, body sizes, self-perceived physical attractiveness, etc.), personality, and short-term mating motivation.

Participants were told that, as part of their compensation for the study, they would be provided with their personal social profile scores and their standing on different dimensions, relative to 10,000 previous respondents in the United States. This feedback enabled the manipulation of short-term mate value. 
Ostensibly based on their responses, we provided participants with direct feedback about their short-term mate value while holding constant their beliefs about their value as friends, siblings, coworkers, and longterm committed/romantic partners. In the high mate value condition $(n=291)$, participants were told that they compared favorably as a short-term sexual partner-that they scored much higher than the population average (top 20\%) and higher than their scores in other relationship domains. In the low mate value condition $(n=293)$, participants were told that the compared less favorably as a short-term sexual partner-that they scored lower than the population average (bottom 45\%) and lower than their scores in other relationship domains.

Post-Manipulation Measures. We assessed self-perceived mate values and life satisfaction $\left(\mathrm{a}_{2 \mathrm{~A}}=\right.$ $.92, \mathrm{a}_{2 \mathrm{~B}}=.91$ ) as in Study 1 . In addition, participants completed the three items of the behavior facet subscale of the Sociosexual Orientation Inventory (e.g., "How many different partners do you foresee yourself having sex with during the next five years?"; Simpson \& Gangestad, 1991; $a_{2 A}=.68, a_{2 B}=.72$ ). To assess robustness of effects in the face of alternative constructs, participants reported in Study $2 \mathrm{~A}$ their self-perceived desirability as a friend, sibling, or coworker to members of the opposite sex, compared to same-sex peers (e.g., "Compared with other men [women] you know who are about your age, how desirable do women [men] find you as a friend?") and in Study 2B their self-esteem (e.g., "I take a positive attitude toward myself"; two items from Rosenberg, 1965; $a=.85$ ).

\section{Results}

Manipulation Check. In Study 2A, participants rated high-desirable photographs $(M=7.26, S D=1.45)$ as significantly more sexually desirable than average- $(M=5.74, S D=1.53, t(672)=32.33, p<.001)$ and low-desirable $(M=4.03, S D=1.35, t(672)=50.94, p<.001)$ photographs, and rated average-desirable photographs as significantly more sexually desirable than low-desirable photographs $(t(672)=-32.50, p<$ $.001)$.

However, our attempts to manipulate participants' beliefs about their short-term mate value were unsuccessful in both Study $2 \mathrm{~A}\left(M_{\text {high }}=5.15, S D=2.27, M_{\text {low }}=5.10, S D=2.42, t(671)=0.26, p=.79\right)$ and in Study $2 \mathrm{~B}\left(M_{\text {high }}=4.95, S D=2.38, M_{\text {low }}=4.89, S D=2.30, t(581)=0.34, p=.74\right)$. These non-differences characterized both male and female participants, and those in both uncommitted and committed relationships ( $p s>$.34). We thus collapsed across experimental conditions and assessed whether the correlational findings here replicated those from Study 1 . We return to the manipulation failure in the General Discussion.

Replication of Study 1. Consistent with Study 1 , the associations between self-perceived long-term and short-term mate value were of small to moderate magnitude (2A: $r=.33$; 2B: $r=.12$ ); self-perceived longterm mate value positively predicted life satisfaction across participant sex and relationship status (2A: $r=.33, p<.001 ; 2 \mathrm{~B}: r=.51, p<.001$; Table 1); and the Sex 'Relationship Status ' Short-term Mate value three-way interaction on life satisfaction obtained (2A: $\beta=-.41,95 \% \mathrm{Cl}[-.71,-.11], t(664)=-2.71, p=.007$, $R^{2}=.09 ; 2 \mathrm{~B}: \beta=-.34,95 \% \mathrm{Cl}[-.67,-.01], t(575)=-2.02, p=.043, R^{2}=.17$; Figures $3 \mathrm{~A}$ and $\left.4 \mathrm{~A}\right)$. The Sex' 
Short-term Mate value two-way interaction was significant for uncommitted participants $(2 \mathrm{~A}: \beta=.47,95 \%$ $\mathrm{Cl}[.24, .69], t(310)=4.08, p<.001 ; 2 \mathrm{~B}: \beta=.31,95 \% \mathrm{Cl}[.02, .60], t(209)=2.11, p=.036)$, but nonsignificant for committed participants $(2 \mathrm{~A}: \beta=.06, t(354)=0.57, p=.57 ; 2 \mathrm{~B}: \beta=-.03, t(366)=-0.30, p$ $=.77$; Table 1).

Moderation by Short-term Mating Motivation. First, an ANOVA revealed a main effect of relationship status on short-term mating motivation, with uncommitted participants reporting more short-term mating motivation than committed participants $(2 \mathrm{~A}: F(1,669)=72.12, p<.001 ; 2 \mathrm{~B}: F(1,579)=39.42, p<.001)$, and a main effect of sex, with men reporting more short-term mating motivation than women (2A: $F(1$, $669)=114.59, p<.001 ; 2 \mathrm{~B}: F(1,579)=72.93, p<.001)$. These effects were qualified, however, by the predicted Sex ' Relationship Status interaction $\left(2 \mathrm{~A}: F(1,669)=7.27, p=.007, R^{2}=.22 ; 2 \mathrm{~B}: F(1,579)=\right.$ $8.72, p=.003, R^{2}=.17$; Figures 3B and 4B). Men in uncommitted relationships were especially likely to be motivated toward short-term mating, likely explaining why their self-perceived short-term mate value positively predicted their life satisfaction in Study 1.

Second, the predicted Short-term Mating Motivation' Short-term Mate value two-way interaction on life satisfaction conceptually replicated the sex- and relationship-specific links between short-term mate value and life satisfaction (2A: $\beta=.11,95 \% \mathrm{Cl}[.03, .19], t(668)=2.70, p=.007 . R^{2}=.02 ; 2 \mathrm{~B}: \beta=.10,95 \%$ $\left.\mathrm{Cl}[.02, .18], t(579)=2.46, p=.014 . R^{2}=.03\right)$. Probing the interaction at one standard deviation above and below the mean of short-term mating motivation (Aiken \& West, 1991), we see that, for those high in short-term mating motivation, self-perceived short-term mate value strongly and positively predicted their life satisfaction $(2 \mathrm{~A}: \beta=.33,95 \% \mathrm{Cl}[.14, .52], t(668)=3.41, p<.001 ; 2 \mathrm{~B}: \beta=.36,95 \% \mathrm{Cl}[.17, .54], t(579)=$ $3.77, p=.002)$; this was not the case for those low in short-term mating motivation $(2 \mathrm{~A}: \beta=-.11, t(668)=$ $-1.28, p=.20 ; 2 \mathrm{~B}: \beta=-.03, t(579)=-0.31, p=.76$; Figures $3 \mathrm{C}$ and $4 \mathrm{C})$. These findings demonstrate that individual differences in short-term mating motivation can moderate the link between self-perceived short-term mate value and life satisfaction, illustrating the functional specificity of these relations: Shortterm mate value only serves as a useful cue for life satisfaction for those who are motivated toward short-term mating.

\section{Life Satisfaction and Mating-Related Behavior.}

Given that self-perceived short-term mate value predicts life satisfaction for only uncommitted men, we examined whether life satisfaction statistically mediated the association between short-term mate value and short-term mating behavior for these participants. Using 5,000 bootstrapped iterations to compute a bias-corrected $95 \%$ confidence interval $(\mathrm{Cl})$, we found that the indirect effect was significant $(2 \mathrm{~A}: \beta=.06$, $95 \% \mathrm{Cl}=[.01, .11], p=.027 ; 2 \mathrm{~B}: \beta=.11,95 \% \mathrm{Cl}=[.04, .19], p<.001)$ (Figure 5). Although the direct effect was also significant, $(2 \mathrm{~A}: \beta=.42,95 \% \mathrm{Cl}=[.30, .54], p<.001 ; 2 \mathrm{~B}: \beta=.36,95 \% \mathrm{Cl}=[.21, .52], p<.001)$, a significant proportion of the total effect was mediated by life satisfaction (2A: $\beta=.12 ., 95 \% \mathrm{Cl}=[.02, .24]$, $p=.02 ; 2 \mathrm{~B}: \beta=.23,95 \% \mathrm{Cl}=[.09, .42], p<.001)$. This finding provides preliminary evidence for a possible functional role of life satisfaction in directing behavioral resources toward facilitating goal-specific achievement. 
Robustness Checks. In Study 2A, after controlling for participant self-evaluations as a friend, sibling, and coworker, self-perceived long-term mate value continued to predict life satisfaction $(\beta=.31,95 \% \mathrm{Cl}[.23$, .38], $t(666)=7.95, p<.001)$, and self-perceived short-term mate value continued to significantly predict life satisfaction for uncommitted men $(\beta=.31,95 \% \mathrm{Cl}[.19, .45], t(199)=4.81, p<.001)$.

Consistent with previous research, we found in Study 2B that life satisfaction and self-esteem were highly correlated, $r=0.78, p<.001$. However, self-perceived long-term mate value significantly predicted life satisfaction above and beyond self-esteem $(\beta=.16,95 \% \mathrm{Cl}[.10, .22], t(580)=5.40, p<.001)$, and selfperceived short-term mate value significantly predicted life satisfaction for uncommitted men above and beyond self-esteem $(\beta=.18,95 \% \mathrm{Cl}[.06, .31], t(142)=2.93, p=.004)$.

Self-perceived mate value carried useful predictive information above and beyond that of both one's selfperceived value as a partner for other types of social relationships and general self-esteem. These results rule out an alternative explanation in which a general inclination toward maintaining a positive self-view leads both to enhanced self-perceived mate value and life satisfaction.

\section{Discussion}

The findings of Studies $2 \mathrm{~A}$ and $2 \mathrm{~B}$ closely replicated the findings of Study 1 and demonstrated that individual differences in short-term mating motivation moderate the link between self-perceived shortterm mate value and life satisfaction. Furthermore, Studies $2 \mathrm{~A}$ and $2 \mathrm{~B}$ found that life satisfaction partially mediates the association between short-term mate value and relevant short-term mating behaviors. [2] Last, these findings also demonstrated their robustness against other forms of selfevaluation. In all, Studies 2A and 2B provide consistent and converging evidence that life satisfaction is systematically calibrated to long-term and short-term mate values in functionally cogent ways.

Studies 2, however, failed to assess the causal relationship between self-perceived short-term mate value and life satisfaction, as participants' beliefs about their short-term mate value was robust against both our experimentally manipulated feedback and implicit social comparison; in the General Discussion, we address the possibility that self-perceived mate value may be relatively stable over short periods of time.

[2] We propose a mediational model in which self-perceived short-term mate value would calibrate life satisfaction as a means of facilitating short-term mating behavior. One could posit an alternative, however, in which self-perceived short-term mate value would shape short-term mating behavior as a means of facilitating life satisfaction. We tested this alternative mediation model and, as with our focal model, found support for it from Studies 2A and 2B; see Supplement. This is as one would expect, however. Because we measured self-perceived short-term mate value, short-term unrestricted mating behavior, and life satisfaction contemporaneously, the current data structure cannot be used to infer causal relationships among these three variables. If the correlational relationships enable statistical mediation for one of these models, they are highly likely to do the same for the other. Thus, both models remain empirically plausible, although we believe that other research (Luhmann et al., 2013; Lyubomirsky et al., 2005) lends credence to the model proposed here. Regardless, differentiating these alternatives 
would be valuable, requiring designs in which short-term mating behavior and life satisfaction are successfully manipulated experimentally.

\section{Study 3}

In Studies 2A and 2B, sex differences in the association between self-perceived short-term mate value and life satisfaction were predicted by sex differences in short-term mating motivation. To examine the causal effect of mating goal on the relevance of mate value for life satisfaction, we attempted to experimentally manipulate women's short-term mating motivation to be similar to that of men. We hypothesized that if uncommitted women (but not committed women) are exposed to a manipulation designed to motivate them toward short-term mating, they would exhibit a pattern more similar to uncommitted men-a stronger positive association between self-perceived short-term mate value and life satisfaction.

\section{Method}

Participants. Based on the weighted mean effect size for three-way interactions across previous studies, we computed an a priori required sample size of 151 participants using a two-tailed test, $f^{2}=.10, a=.05$, and power $=.80$. We collected data from an introductory psychology subject pool at a large Southwestern university and analyzed data from 157 women $(M=19.0$ years, $S D=1.06)$ who self-reported as heterosexual and passed an attention check.

Materials and Procedure. Employing a procedure slightly modified from one successfully used in previous research (Ainsworth \& Maner, 2012; Maner et al., 2007), participants randomly assigned to the short-term mating condition $(n=75)$ listed five instances in which they felt sexual desire or arousal "from afar-that is, without having interacted with the person yet," and then visualized in detail for approximately 5 minutes an experience involving intense sexual desire. The instruction was written to focus participants away from thinking about long-term mating instances and toward short-term mating instances. Participants assigned to the control condition $(n=82)$ instead listed and visualized instances in which they felt loved and cared for by a family member.

Participants then completed the same measures of self-perceived mate value and life satisfaction as in previous studies.

\section{Results}

Six independent coders rated how much the women participants would feel sexually aroused, romantically aroused, and loving and caring in the situation they described ( $1=$ Not at all; $7=$ Extremely). Raters predicted that women in the mating condition are more likely to feel sexually aroused $\left(M_{\text {mating }}=\right.$ $\left.4.28, S D=1.49 ; M_{\text {control }}=1.05, S D=0.25 ; t(155)=19.34, p<.001\right)$ and romantically aroused $\left(M_{\text {mating }}=\right.$ $\left.3.78, S D=1.22 ; M_{\text {control }}=1.95, S D=0.45 ; t(155)=12.69, p<.001\right)$ than women in the control condition, whereas they predicted that women in the control condition are more likely to feel loving and cared for 
$\left(M_{\text {mating }}=3.17, S D=1.06 ; M_{\text {control }}=5.17, S D=0.91 ; t(155)=-12.76, p<.001\right)$ than women in the mating condition. The intraclass correlation coefficients (ICCs) between 6 raters indicated good to excellent reliabilities on the ratings (ICCs $=0.96$ for sexually aroused, 0.86 for romantically aroused, 0.91 for loving and cared for).

Analyses regressing on Manipulated Short-term Mating Motivation (contrast coded: -0.5 for control condition, 0.5 for short-term mating condition), Short-term Mate value, and Relationship Status revealed the hypothesized three-way interaction on life satisfaction, $\beta=-.70,95 \% \mathrm{Cl}[-1.32,-.08], t(149)=-2.22, p=$ $.028, R^{2}=.11$ (Figure 6).[3]

For uncommitted women, the predicted Short-term Mating Motivation 'Short-term Mate value interaction was significant, $\beta=.49,95 \% \mathrm{Cl}[.09, .90], t(77)=2.43, p=.017, R^{2}=.16$. For uncommitted women exposed to the short-term mating motivation manipulation, self-perceived short-term mate value positively predicted life satisfaction, $\beta=.58,95 \% \mathrm{Cl}[.25, .91] t(32)=3.57, p=.001$, similar to the pattern previously found only for uncommitted men; for uncommitted women in the control condition, however, there was no such relationship, $\beta=.08, t(45)=0.66, p=.51$. In contrast, for women in committed relationships, the Short-term Mating Motivation 'Short-term Mate value interaction was nonsignificant, $\beta$ $=-.20, t(72)=-0.84, p=.40$. Indeed, if anything, there was a marginally significant negative association between short-term mate value and life satisfaction for women exposed to the short-term mating manipulation, $\beta=-.31, t(39)=-1.94, p=.06$, such that committed women who believed themselves to be low in short-term mate value tended to be highly satisfied with their lives; there was no significant association between self-perceived short-term mate value and life satisfaction for committed women in the control condition, $\beta=-.10, t(33)=-0.57, p=.57$.

\section{Discussion}

Study 3 provides corroborating experimental evidence: Encountering a manipulation designed to engage short-term mating motivation can cause women in uncommitted relationships-who by default tend to be relatively low in short-term mating motivation-to psychologically operate somewhat like uncommitted men, in that their self-perceived short-term mate value positively predicted their life satisfaction. These findings support a functional conceptualization of life satisfaction, showing that currently active mating goals can shape the extent to which goal-specific self-perceived mate value predicts life satisfaction

\section{Meta-Analyses of the Findings from Studies 1-3}

To assess the reliability of findings across Studies 1-3 (total $n=2,235$ ), we performed random effect meta-analyses on the standardized coefficients. Based on guidelines from Funder and Ozer (2019), the meta-analyses revealed a large effect size for the association between self-perceived long-term mate value and life satisfaction for men and women regardless of relationship status (overall $r=.35,95 \% \mathrm{Cl}$ $[.31, .38])$ and a large effect size for the association between self-perceived short-term mate value on life satisfaction for those with short-term mating motivation-single uncommitted men (Studies 1, 2A, and 2B) and single uncommitted women whose short-term mating motivation was experimentally engaged 
(Study 3) (overall $r=.33,95 \% \mathrm{Cl}[.26, .39])$. Especially significant, we observed a moderate effect of Sex ' Relationship Status 'Short-term Mate value three-way interaction on life satisfaction, $\beta=-.37,95 \% \mathrm{Cl}$ $[-.54,-.21] ; z=-4.38, p<.001$; heterogeneity $Q(3)=1.37, p=.71 ; R^{2}=.08$.[4] The other focal analyses were also significant across multiple replications (Table 2).

Table 2. Meta-analytic Effects Across Studies 1-3.

\begin{tabular}{|llll|}
\hline & $\begin{array}{l}\text { Standardized } \\
\text { coefficient }\end{array}$ & $\begin{array}{l}95 \% \text { confidence } \\
\text { interval }\end{array}$ & $R^{2}$ \\
\hline Life satisfaction predicted by Long-term mate value & $.35^{\star \star \star}$ & {$[.21, .49]$} & .12 \\
\hline $\begin{array}{l}\text { Life satisfaction predicted by Short-term mate } \\
\text { value' Sex' Relationship status }\end{array}$ & $-.37^{\star \star \star}$ & {$[-.54,-.21]$} & .08 \\
$\begin{array}{l}\text { Short-term mating motivation predicted by } \\
\text { Sex'Relationship status }\end{array}$ & $-.43^{\star \star}$ & {$[-.64,-.22]$} & .20 \\
$\begin{array}{l}\text { Life satisfaction predicted by Short-term mate } \\
\text { value'Short-term mating motivation }\end{array}$ & $.11^{\star \star}$ & {$[.05, .16]$} & .02 \\
\hline
\end{tabular}

$\star p<.05, * \star p<.01, * \star \star p<.001$

[3] As expected, self-perceived short-term mate value was unaffected by the mating motivation manipulation, $t(155)=-1.25, p>.21$.

[4] In Study 3, we experimentally manipulated short-term mating motivation, assessing the hypothesis that the predicted positive association between self-perceived short-term mate value and life satisfaction would appear for uncommitted women for whom short-term mating motivation was experimentally manipulated-just as it does for uncommitted men under default circumstances. To make the analysis in Study 3 comparable to those in Studies 1 and 2 for this meta-analysis, we coded Study 3 women in the short-term mating condition as we did male participants in Studies 1 and 2, and the Study 3 women in the control condition as we did women participants in Studies 1 and 2. Note that replicating the metaanalyses excluding Study 3 does not alter assessments of statistical significance or the conclusions, three-way interaction $\beta=-.35,95 \% \mathrm{Cl}[-.52,-.18]$.

\section{General Discussion}

If life satisfaction is a subjective indicator of potential goal achievement, active and fundamentally important goals should shape the extent to which life satisfaction is calibrated to cues linked to likely success on these goals. We focused on mating goals because they are of fundamental concern to nearly all people at some point in their lives and because differences in motivation for different mating strategies enable nuanced hypotheses not readily derived by other conceptual approaches. Because mate value takes different forms depending on whether one is adopting long-term versus short-term strategies, and because these different strategies tend to be differentially relevant to men and women and to people 
in uncommitted versus committed relationships, the implications of mate value for life satisfaction are likely to be nuanced in sex- and relationship-specific functional ways.

Across four studies, we found consistent, theoretically coherent patterns of results revealing that both chronically active and experimentally activated mating goals predict the association between selfperceived mate value and life satisfaction. Whereas higher self-perceived long-term mate value predicted greater life satisfaction for both men and women regardless of current relationship status (Studies 1, 2A, and $2 \mathrm{~B}$ ), higher self-perceived short-term mate value predicted greater life satisfaction only for those motivated towards short-term relationships-single uncommitted men (Studies 1, 2A, and 2B), individuals dispositionally motivated towards short-term mating relationships (Studies $2 \mathrm{~A}$ and $2 \mathrm{~B}$ ), and single uncommitted women whose short-term mating motivation was experimentally heightened (Study 3 ). Internal meta-analyses across the four studies revealed the above findings to be reliable and robust.

\section{Alternative Explanations}

Study 3's experimental manipulation of women's short-term mating motivation directly demonstrated that engagement of short-term mating motivation causes a significantly stronger association between selfperceived short-term mate value and life satisfaction for the uncommitted women. Given the experimental failures of Studies 2, however, we were not able to assess the causal relationship between self-perceived mate value and life satisfaction. Although we believe the functional logic articulated makes it likely that self-perceived mate value causes life satisfaction, one could hypothesize a reverse causal pathway, such that greater life satisfaction enhances self-views of mate value because such satisfied individuals are also more optimistic about their potential success on mating (Lucas et al., 1996; Schimmack et al., 2004). Alternatively, one might hypothesize that people with a general inclination to view themselves favorably may possess both an enhanced self-view of mate value and a belief that one's life is generally of high quality-thereby generating a positive correlation between self-perceived mate value and life satisfaction. Although apparently reasonable on their faces, such alternatives cannot logically account for the pattern of findings presented-(1) for the relatively low correlations between long- and short-term mate value, (2) for differences in how long- and short-term mate value predicted life satisfaction, (3) for the lack of positive association between short-term mate value and life satisfaction for men in committed relationships, (4) for the lack of positive association between short-term mate value and life satisfaction for women (except for uncommitted women exposed to our manipulation of shortterm mating motivation in Study 3), or (5) for the robustness of the link between mate value and life satisfaction against other self-evaluations. The specificity of the observed effects cannot be readily derived from conceptualizations focused on positive illusion biases caused by life satisfaction or from general self-enhancement.

One might argue that the weak association between women's short-term mate value and life satisfaction results from women's generally negative responses to sexual valuation (Calogero, 2004; Fairchild \& Rudman, 2008). However, women's own beliefs about their short-term mate value were not negatively associated with their life satisfaction. Moreover, for uncommitted women exposed to our manipulation of 
short-term mating motivation, short-term mate value positively predicted life satisfaction. Such results are in line with findings that being sexually valued by a committed mating partner is positively linked to women's relationship satisfaction (Meltzer, 2020; Meltzer et al., 2017).

\section{Implications and Future Directions}

Function of Life Satisfaction. Extending the growing literature on the adaptive functionality of inner experiential states, the current research offers a useful framework for reconceptualizing life satisfaction. Our findings support a novel hypothesis that life satisfaction serves as part of an internal psychological system that monitors individuals' success or failure in managing important social challenges. Consistent with this, life satisfaction was predicted by cues implying success or failure toward the relevant goals (e.g., short-term mate value) only to the extent those goals were dispositionally important and/or acutely engaged (e.g., for those interested in short-term relationships).

Longitudinal studies suggest that life satisfaction is prospectively associated with and precedes desirable characteristics, resources, and adaptive behaviors (Lyubomirsky et al., 2005). Consistent with these findings, we found that feelings of life satisfaction may direct behavioral resources toward facilitating success of relevant goals. Life satisfaction of uncommitted men statistically mediated the association between their self-perceived short-term mate value and short-term mating behavior. Our finding is in line with longitudinal studies that suggest life satisfaction is associated with and directly precedes various beneficial downstream consequences, as well as behaviors paralleling success (Luhmann et al., 2013; Lyubomirsky et al., 2005), although our research design does not allow for dispositive conclusions ruling out alternative mechanisms (e.g., see Supplement). Future research might profitably explore the full functional process by investigating how life satisfaction, calibrated to cues related to potential success in desired goal pursuit, causes downstream goal-enhancing behaviors.

Individual Differences in Determinants of Life Satisfaction. People vary greatly in their life satisfaction. The specificity of our findings suggests that a range of individual differences contribute importantly to differences in life satisfaction.

First, differences in goal priorities are likely to contribute to differences in life satisfaction. Because different cues are useful for assessing likely success for different goals, and because people differ in which goals they prioritize, one would expect life satisfaction to be selectively calibrated to different goalspecific cues for different people. To better predict life satisfaction, one should consider individual differences in goal priority and likely success in those prioritized goals.

Second, individuals might differ in life satisfaction because, even when life satisfaction is shaped by a similar goal pursuit, there may be substantial differences in how life satisfaction is calibrated, given the relevance of different features as cues to goal success for different individuals. For example, because different features shape mate value for men and women (Li et al., 2002), life satisfaction of men and women may track different features (Ko \& Suh, 2019). 
Last, one's ecology and culture might influence which fundamental goals are chronically active and which indicators represent goal achievement, thereby influencing life satisfaction. For instance, given that women in areas of high income inequality (where female mating competition is enhanced) more frequently post sexualized photographs of themselves on social media (Blake et al., 2018), self-perceived short-term mate value might contribute more to the life satisfaction of women who live in environments where the incentive for sexualization is high. Because mate qualities and mating strategies are shaped differently by ecology and culture (Marlowe, 2004; Pillsworth, 2008), future research might profitably investigate how life satisfaction is calibrated by different valuations and criteria for mating partners across different ecologies and cultures.

\section{Nuanced Conceptions of Self-perceived Mate Value}

The current study highlights the usefulness of differentiating between long-term and short-term mate value. Not only were self-perceived long-and short-term mate value only modestly correlated, but they differentially predicted life satisfaction for different individuals, and when different mating goals were engaged. Future work may benefit from examining how people assess their long- vs. short-term mate value given that different factors are desired for long- vs. short-term mating relationships (Li \& Kenrick, 2006), and whether distinctive forms of self-perceived mate value have unique implications for other important psychological variables.

Our findings further suggest that people may have relatively reliable beliefs about their mate value. Although we attempted to shift personal beliefs about short-term mating desirability via implicit social comparison and direct feedback, we were unsuccessful; for adults who have been mating-motivated for some time, self-perceived mate value may be stable in the short-term (Edlund \& Sagarin, 2014).

Specifically, because both men and women highly prioritize physical attractiveness for short-term mating relationships while also believing it difficult to intentionally control or alter physical attractiveness in the absence of great effort (Ben Hamida et al., 1998), experimentally manipulating self-perceived short-term mate value may be quite difficult. Future research may profitably investigate factors that shape mate value stability and change.

\section{Conclusion}

Life satisfaction may partially function to index potential success on fundamentally adaptive, active goals and to motivate action toward those goals, thereby promoting individuals' success. Four studies demonstrated that when people believe they possess characteristics predictive of success on active important goals, they are more likely to be satisfied with their lives. Building on a growing body of literature examining the functional significance of subjective states, this framework highlights a novel way of conceptualizing life satisfaction. This functional approach to understanding life satisfaction may help synthesize the existing literature and generate novel predictions, thereby advancing the field toward a richer understanding of subjective human well-being. 


\section{Declarations}

Acknowledgement. This research was partially supported by funds granted to Steven L. Neuberg by the Arizona State University Foundation for a New American University, and to Ahra Ko by the Arizona State University Graduate and Professional Student Association

Conflict of interest statement: The authors declare they have no conflicts of interest with respect to this work.

Compliance of ethical standard statement: In the conduct of these studies, we complied with APA ethical standards in the treatment of our samples. This research received approval from the Institutional Review Board of the Arizona State University.

Informed consent: We received informed consent from all individuals participating in the present research.

\section{References}

Aiken, L. S., \& West, S. G. (1991). Multiple regression: Testing and interpreting interactions. Thousand Oaks: Sage.

Ainsworth, S. E., \& Maner, J. K. (2012). Sex begets violence: Mating motives, social dominance, and physical aggression in men. Journal of Personality and Social Psychology, 103(5), 819-829. https://doi.org/10.1037/a0029428

Back, M. D., Penke, L., Schmukle, S. C., \& Asendorpf, J. B. (2011). Knowing your own mate value: Sexspecific personality effects on the accuracy of expected mate choices. Psychological Science, 22(8), 984-989. https://doi.org/10.1177/0956797611414725

Bailey, D. H., Durante, K. M., \& Geary, D. C. (2011). Men's perception of women's attractiveness is calibrated to relative mate value and dominance of the women's partner. Evolution and Human Behavior, 32(2), 138-146. https://doi.org/10.1016/j.evolhumbehav.2010.08.004

Barrett, H. C., \& Kurzban, R. (2006). Modularity in cognition: Framing the debate. Psychological Review, 113(3), 628-647. https://doi.org/10.1037/0033-295X.113.3.628

Beall, A. T., \& Tracy, J. L. (2017). Emotivational psychology: How distinct emotions facilitate fundamental motives. Social and Personality Psychology Compass, 11(2), 1-17. https://doi.org/10.1111/spc3.12303

Ben Hamida, S., Mineka, S., \& Bailey, J. M. (1998). Sex differences in perceived controllability of mate value: An evolutionary perspective. Journal of Personality and Social Psychology, 75(4), 953-966. https://doi.org/10.1037//0022-3514.75.4.953 
Bird, B. M., Carre, J. M., Knack, J. M., \& Arnocky, S. (2016). Threatening men's mate value influences aggression toward an intrasexual rival: The moderating role of narcissism. American Journal of Psychology, 129(2), 169-183. https://doi.org/10.5406/amerjpsyc.129.2.0169

Blake, K. R., Bastian, B., Denson, T. F., Grosjean, P., \& Brooks, R. C. (2018). Income inequality not gender inequality positively covaries with female sexualization on social media. Proceedings of the National Academy of Sciences, 115(35), 8722-8727. https://doi.org/10.1073/pnas.1717959115

Brunstein, J. C., Schultheiss, O. C., \& Grässman, R. (1998). Personal goals and emotional well-being: The moderating role of motive dispositions. Journal of Personality and Social Psychology, 75(2), 494-508. https://doi.org/10.1037/0022-3514.75.2.494

Bugental, D. B. (2000). Acquisition of the algorithms of social life: A domain based approach. Psychological Bulletin, 126(2), 187-219. https://doi.org/10.1037/0033-2909.126.2.187

Buss, D. M., \& Schmitt, D. P. (1993). Sexual strategies theory: An evolutionary perspective on human mating. Psychological Review, 100(2), 204-232. https://doi.org/10.1037/0033-295X.100.2.204

Buston, P. M., \& Emlen, S. T. (2003). Cognitive processes underlying human mate choice: The relationship between self-perception and mate preference in Western society. Proceedings of the National Academy of Sciences of the United States of America, 100(15), 8805-8810.

https://doi.org/10.1073/pnas.1533220100

Calogero, R. M. (2004). A test of objectification theory: The effect of the male gaze on appearance concerns in college women. Psychology of Women Quarterly, 28, 16-21.

Carver, C. S., \& Scheier, M. F. (1990). Origins and functions of positive and negative affect: A controlprocess view. Psychological Review, 97(1), 19-35. https://doi.org/10.1037/0033-295X.97.1.19

Clark, R., \& Hatfield, E. (1989). Gender differences in receptivity to sexual offers. In Journal of Psychology \& Human Sexuality (Vol. 2, Issue 1, pp. 39-55). https://doi.org/10.1300/J056v02n01_04

Cohen, J., Cohen, P., West, S. G., \& Aiken, L. S. (2003). Applied multiple regression/correlation analysis for the behavior sciences. Lawrence Erlbaum Associates, Inc.

Conroy-Beam, D., \& Buss, D. M. (2016). Do mate preferences influence actual mating decisions? Evidence from computer simulations and three studies of mated couples. Journal of Personality and Social Psychology, 111(1), 53-66. https://doi.org/10.1037/pspi0000054

Conroy-Beam, D., Goetz, C. D., \& Buss, D. M. (2015). Why do humans form long-term mateships? An evolutionary game-theoretic model. Advances in Experimental Social Psychology, 51(1), 1-39. https://doi.org/10.1016/bs.aesp.2014.11.001 
Conroy-Beam, D., Roney, J. R., Lukaszewski, A. W., Buss, D. M., Asao, K., Sorokowska, A., Sorokowski, P., Aavik, T., Akello, G., Alhabahba, M. M., Alm, C., Amjad, N., Anjum, A., Atama, C. S., Duyar, D. A., Ayebare, R., Batres, C., Bendixen, M., Bensafia, A., ... Zupančič, M. (2019). Assortative mating and the evolution of desirability covariation. Evolution and Human Behavior, 40(5), 479-491.

https://doi.org/10.1016/j.evolhumbehav.2019.06.003

Diener, E., Emmons, R., Larsen, J., \& Griffin, S. (1985). The satisfaction with life scale. Journal of Personality Assessmemt, 49(1), 71-75. https://doi.org/10.1207/s15327752jpa4901_13

Diener, E., \& Fujita, F. (1995). Resources, personal strivings, and subjective well-being: A nomothetic and idiographic approach. Journal of Personality and Social Psychology, 68(5), 926-935.

https://doi.org/10.1037/0022-3514.68.5.926

Diener, E., Gohm, C. L., Suh, E. M., \& Oishi, S. (2000). Similarity of the relations between marital status and subjective well-being across cultures. Journal of Cross-Cultural Psychology, 31(4), 419-436.

https://doi.org/10.1177/0022022100031004001

Diener, E., Wolsic, B., \& Fujita, F. (1995). Physical attractiveness and subjective well-being. Journal of Personality and Social Psychology, 69(1), 120-129.

http://dx.doi.org.ezproxy1.lib.asu.edu/10.1037/0022-3514.69.1.120

Edlund, J. E., \& Sagarin, B. J. (2014). The mate value scale. Personality and Individual Differences, 64, 72-77. https://doi.org/10.1016/j.paid.2014.02.005

Fairchild, K., \& Rudman, L. A. (2008). Everyday stranger harassment and women's objectification. Social Justice Research, 21, 338-357. https://doi.org/10.1007/s11211-008-0073-0

Funder, D. C., \& Ozer, D. J. (2019). Evaluating Effect Size in Psychological Research: Sense and Nonsense. Advances in Methods and Practices in Psychological Science, 2(2), 156-168.

https://doi.org/10.1177/2515245919847202

Gangestad, S. W., \& Simpson, J. A. (2000). The evolution of human mating: Trade-offs and strategic pluralism. Behavioral and Brain Sciences, 23(4), 573-587. https://doi.org/10.1017/S0140525X0000337X

Geary, D. C. (2000). Evolution and proximate expression of human paternal investment. Psychological Bulletin, 126(1), 55-77. https://doi.org/10.1037/0033-2909.126.1.55

Gutierres, S. E., Kenrick, D. T., \& Partch, J. J. (1999). Beauty, dominance, and the mating game: Contrast effects in self-assessment reflect gender differences in mate selection. Personality and Social Psychology Bulletin, 25(9), 1126-1134. https://doi.org/10.1177/01461672992512006

Haselton, M. G. (2003). The sexual overperception bias: Evidence of a systematic bias in men from a survey of naturally occurring events. Journal of Research in Personality, 37(1), 34-47.

https://doi.org/10.1016/S0092-6566(02)00529-9

Page 20/30 
Haselton, M. G., \& Buss, D. M. (2000). Error management theory: A new perspective on biases in cross-sex mind reading. Journal of Personality and Social Psychology, 78(1), 81-91. https://doi.org/10.1037/00223514.78.1.81

Hill, S. E., Rodeheffer, C. D., Griskevicius, V., Durante, K. M., \& White, A. E. (2012). Boosting beauty in an economic decline: Mating, spending, and the lipstick effect. Journal of Personality and Social Psychology, 103(2), 275-291. https://doi.org/10.1037/a0028657

Hofer, J., \& Chasiotis, A. (2003). Congruence of life goals and implicit motives as predictors of life satisfaction: Cross-cultural implications of a study of Zambian male adolescents. Motivation and Emotion, 27(3), 251-272. https://doi.org/10.1023/A:1025011815778

Kaplan, H. S., Hill, K., Lancaster, J., \& Hurtado, A. M. (2000). A theory of human life history evolution: Diet, intelligence, and longevity. Evolutionary Anthropology, 9(4), 156-185. https://doi.org/10.1002/15206505(2000)9:4<156::AID-EVAN5>3.0.C0;2-7

Kenrick, D. T., Griskevicius, V., Neuberg, S. L., \& Schaller, M. (2010). Renovating the pyramid of needs: Contemporary extensions built upon ancient foundations. Perspectives on Psychological Science, 5(3), 292-314. https://doi.org/10.1177/1745691610369469

Kenrick, D. T., Neuberg, S. L., Zierk, K. L., \& Krones, J. M. (1994). Evolution and social cognition: Contrast effects as a function of sex, dominance, and physical attractiveness. Personality and Social Psychology Bulletin, 20(2), 210-217. https://doi.org/10.1177/0146167294202008

Kirkpatrick, L. A., Waugh, C. E., Valencia, A., \& Webster, G. D. (2002). The functional domain specificity of self-esteem and the differential prediction of aggression. Journal of Personality and Social Psychology, 82(5), 756-767. https://doi.org/10.1037//0022-3514.82.5.756

Ko, A., Pick, C. M., Kwon, J., Barlev, M., Krems, J. A., Varnum, M. E. W., Neel, R., Peysha, M., Boonyasiriwat, W., Brandstätter, E., Crispim, A. C., Cruz, J. E., David, D., David, O. A., de Felipe, R. P., Fetvadjiev, V. H., Fischer, R., Galdi, S., Galindo, O., ... Kenrick, D. T. (2020). Family matters: Rethinking the psychology of human social motivation. Perspectives on Psychological Science, 15(1), 173-201. https://doi.org/10.1177/1745691619872986

Ko, A., \& Suh, E. M. (2019). Does physical attractiveness buy happiness? Women's mating motivation and happiness. Motivation and Emotion, 43(1), 1-11. https://doi.org/10.1007/s11031-018-9717-z

Leary, M. R. (2007). Motivational and emotional aspects of the self. Annual Review of Psychology, 58(1), 317-344. https://doi.org/10.1146/annurev.psych.58.110405.085658

Leary, M. R., \& Baumeister, R. F. (2000). The nature and function of self-esteem: Sociometer theory. Advances in Experimental Social Psychology, 32, 1-62. https://doi.org/10.1016/S0065-2601(00)80003-9 
Leary, M. R., Tambor, E. S., Terdal, S. K., \& Downs, D. L. (1995). Self-esteem as an interpersonal monitor: The sociometer hypothesis. Journal of Personality and Social Psychology, 68(3), 518-530.

https://doi.org/10.1037/0022-3514.68.3.518

Li, N. P., \& Kenrick, D. T. (2006). Sex similarities and differences in preferences for short-term mates: What, whether, and why. Journal of Personality and Social Psychology, 90(3), 468-489.

https://doi.org/10.1037/0022-3514.90.3.468

Li, N. P., Kenrick, D. T., Bailey, J. M., \& Linsenmeier, J. A. W. (2002). The necessities and luxuries of mate preferences: Testing the tradeoffs. Journal of Personality and Social Psychology, 82(6), 947-955. https://doi.org/10.1037/0022-3514.82.6.947

Lucas, R. E., Diener, E., \& Suh, E. M. (1996). Discriminant validity of well-being measures. Journal of Personality and Social Psychology, 71(3), 616-628. https://doi.org/10.1037/0022-3514.71.3.616

Luhmann, M., Hofmann, W., Eid, M., \& Lucas, R. E. (2012). Subjective well-being and adaptation to life events: A meta-analysis. Journal of Personality and Social Psychology, 102(3), 592-615. https://doi.org/10.1037/a0025948

Luhmann, M., Lucas, R. E., Eid, M., \& Diener, E. (2013). The prospective effect of life satisfaction on life events. Social Psychological and Personality Science, 4(1), 39-45. https://doi.org/10.1177/1948550612440105

Luo, S., \& Klohnen, E. C. (2005). Assortative mating and marital quality in newlyweds: A couple-centered approach. Journal of Personality and Social Psychology, 88(2), 304-326. https://doi.org/10.1037/00223514.88.2.304

Lyubomirsky, S., King, L., \& Diener, E. (2005). The benefits of frequent positive affect: Does happiness lead to success? Psychological Bulletin, 131(6), 803-855. https://doi.org/10.1037/0033-2909.131.6.803

Mahadevan, N., Gregg, A. P., \& Sedikides, C. (2018). Is self-regard a sociometer or a hierometer? Selfesteem tracks status and inclusion, narcissism tracks status. Journal of Personality and Social Psychology. https://doi.org/10.1037/pspp0000189

Maner, J. K., Gailliot, M. T., Rouby, D. A., \& Miller, S. L. (2007). Can't take my eyes off you: Attentional adhesion to mates and rivals. Journal of Personality and Social Psychology, 93(3), 389-401. https://doi.org/10.1037/0022-3514.93.3.389

Maner, J. K., \& Miller, S. L. (2014). Hormones and social monitoring: Menstrual cycle shifts in progesterone underlie women's sensitivity to social information. Evolution and Human Behavior, 35(1), 916. https://doi.org/10.1016/j.evolhumbehav.2013.09.001

Marlowe, F. W. (2004). Mate preferences among Hadza hunter-gatherers. Human Nature, 15(4), 365-376. https://doi.org/10.1007/s12110-004-1014-8 
Meltzer, A. L. (2020). Women Can Benefit From Sexual and Physical Valuation in the Context of a Romantic Relationship. Personality and Social Psychology Bulletin, 46(2), 243-257.

https://doi.org/10.1177/0146167219854443

Meltzer, A. L., McNulty, J. K., \& Maner, J. K. (2017). Women like being valued for sex, as long as it is by a committed partner. Archives of Sexual Behavior, 46(2), 475-488. https://doi.org/10.1007/s10508-0150622-1

Neel, R., Kenrick, D. T., White, A. E., \& Neuberg, S. L. (2016). Individual differences in fundamental social motives. Journal of Personality and Social Psychology, 110(6), 887-907.

https://doi.org/10.1037/pspp0000068

Nesse, R. M. (1990). Evolutionary explanations of emotions. Human Nature, 1(3), 261-289. https://doi.org/10.1007/BF02733986

Neuberg, S. L., Kenrick, D. T., \& Schaller, M. (2010). Chapter 21: Evolutionary Social Psychology. Handbook of Social Psychology, 2(January), 761-796.

Neuberg, S. L., \& Schaller, M. (2015). Evolutionary social cognition. In APA handbook of personality and social psychology (Vol. 1, pp. 3-45). https://doi.org/10.1093/oxfordhb/9780199730018.013.0032

Oliver, M. B., \& Hyde, J. S. (1993). Gender differences in sexuality: A meta-analysis. Psychological Bulletin, 114(1), 29-51. https://doi.org/10.1037/0033-2909.114.1.29

Penke, L., Todd, P. M., Lenton, A. P., \& Fasolo, B. (2007). How self-assessments can guide human mating decisions. In G. Geher \& G. F. Miller (Eds.), Mating Intelligence: New insights into intimate relationships, human sexuality, and the mind's reproductive system. (pp. 37-75). Mahwah: Lawrence Erlbaum. https://doi.org/10.1007/978-1-4939-6637-0

Pillsworth, E. G. (2008). Mate preferences among the Shuar of Ecuador: Trait rankings and peer evaluations. Evolution and Human Behavior, 29(4), 256-267.

https://doi.org/10.1016/j.evolhumbehav.2008.01.005

Richerson, P. J., \& Boyd, R. (1998). The evolution of human ultra-sociality. In Ideology, warfare, and indoctrinability (Issue 4, pp. 71-96). New York, NY: Berghahn Books.

https://doi.org/10.1098/rstb.2009.0134

Rosenberg, M. (1965). Society and the adolescent self-image. Princeton University Press.

Schimmack, U., Diener, E., \& Oishi, S. (2002). Life-satisfaction is a momentary judgment and a stable personality characteristic: The use of chronically accessible and stable sources. Journal of Personality, 70(3), 345-384. https://doi.org/10.1111/1467-6494.05008 
Schimmack, U., Oishi, S., Furr, R. M., \& Funder, D. C. (2004). Personality and life satisfaction: A facet-level analysis. Personality and Social Psychology Bulletin, 30(8), 1062-1075.

https://doi.org/10.1177/0146167204264292

Schmitt, D. P. (2005). Sociosexuality from Argentina to Zimbabwe: A 48-nation study of sex, culture, and strategies of human mating. Behavioral and Brain Sciences, 28(2), 247-275.

https://doi.org/10.1017/S0140525X05000051

Schmitt, D. P., Alcalay, L., Allik, J., Ault, L., Austers, I., Bennett, K. L., Bianchi, G., Boholst, F., Borg Cunen, M. A., Braeckman, J., Brainerd, E. G., Caral, L. G. A., Caron, G., Martina Casullo, M., Cunningham, M., Daibo, I., De Backer, C., De Souza, E., Diaz-Loving, R., ... Zupanèiè, A. (2003). Universal sex differences in the desire for sexual variety: Tests from 52 nations, 6 continents, and 13 islands. Journal of Personality and Social Psychology, 85(1), 85-104. https://doi.org/10.1037/0022-3514.85.1.85

Schultheiss, O. C., Jones, N. M., Davis, A. Q., \& Kley, C. (2008). The role of implicit motivation in hot and cold goal pursuit: Effects on goal progress, goal rumination, and emotional well-being. Journal of Research in Personality, 42(4), 971-987. https://doi.org/10.1016/j.jrp.2007.12.009

Simpson, J. A., \& Gangestad, S. W. (1991). Individual differences in sociosexuality: Evidence for convergent and discriminant validity. Journal of Personality and Social Psychology, 60(6), 870-883. https://doi.org/10.1037/0022-3514.60.6.870

Surbey, M. K., \& Brice, G. R. (2007). Enhancement of self-perceived mate value precedes a shift in men's preferred mating strategy. Acta Psychologica Sinica, 39(3), 513-522.

Tracy, J. L. (2014). An evolutionary approach to understanding distinct emotions. Emotion Review, 6(4), 308-312. https://doi.org/10.1177/1754073914534478

Trivers, R. L. (1972). Parental investment and sexual selection. In Parental investment and sexual selection (Vol. 136, pp. 136-179). Cambridge: Biological Laboratories, Harvard University. https://doi.org/10.1002/ajpa.1330400226

Waynforth, D. (2001). Mate choice trade-offs and women's preference for physically attractive men. Human Nature, 12(3), 207-219. https://doi.org/10.1007/s12110-001-1007-9

\section{Figures}




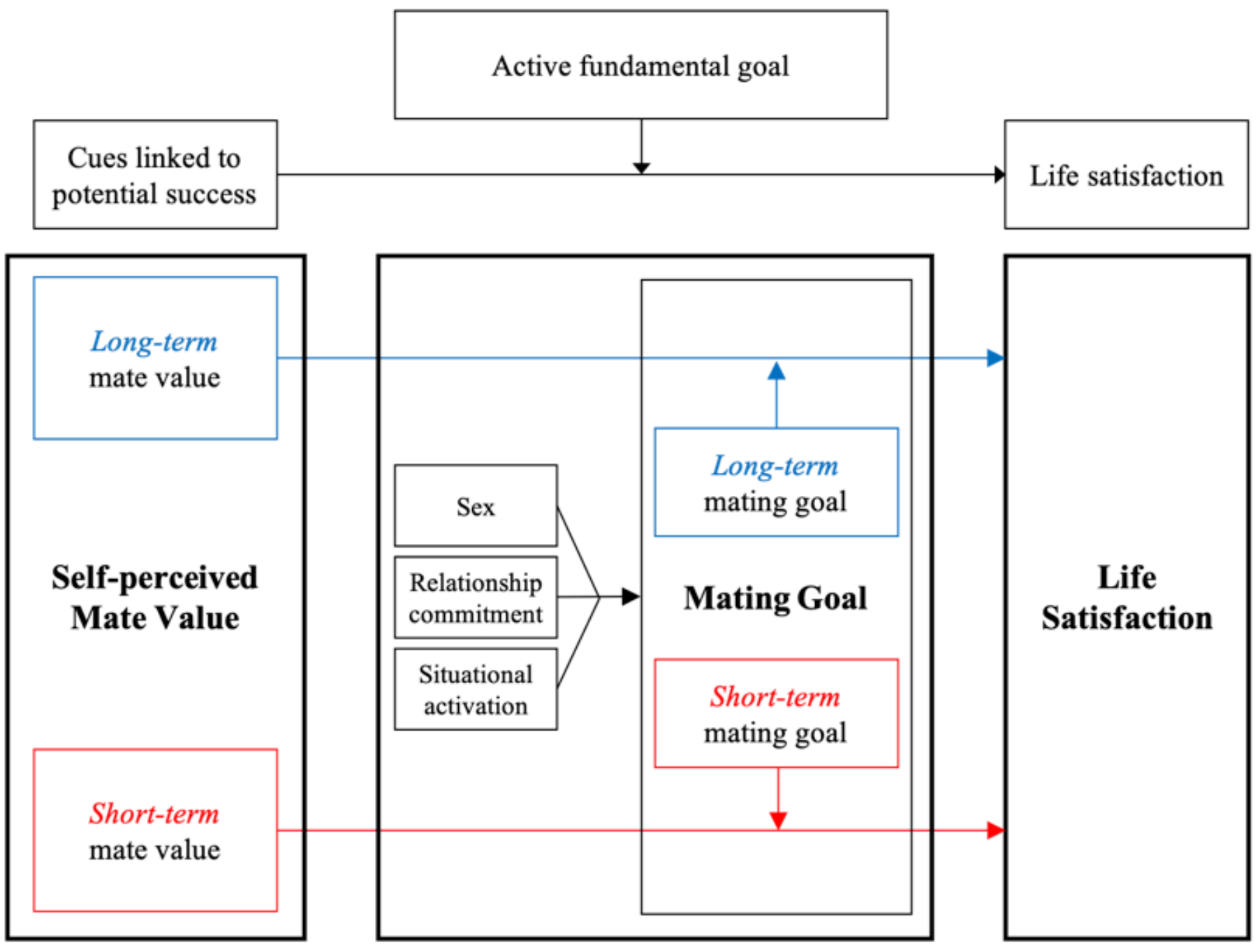

Figure 1

Theoretical model of life satisfaction as calibrated to self-perceived mate values, as a function of sex, relationship status, and active mating goal. 
A
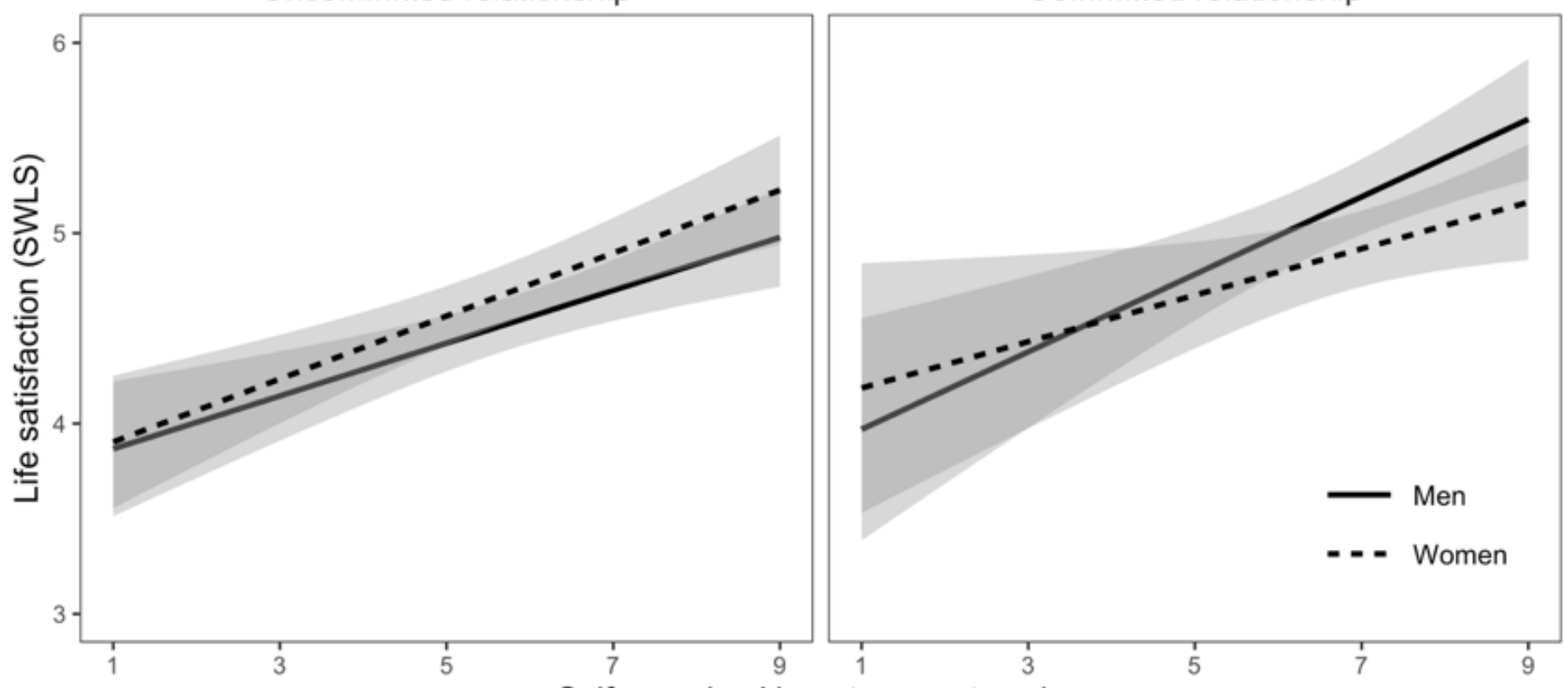

Self-perceived long-term mate value

B

B Uncommitted relationship

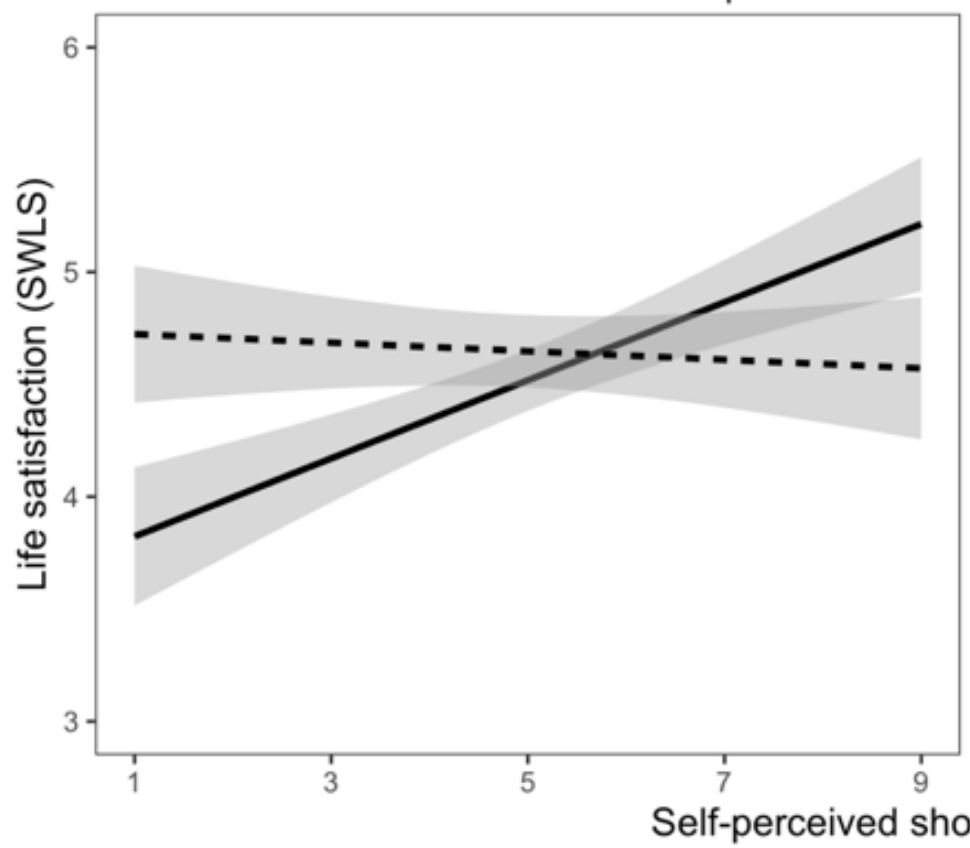

Committed relationship

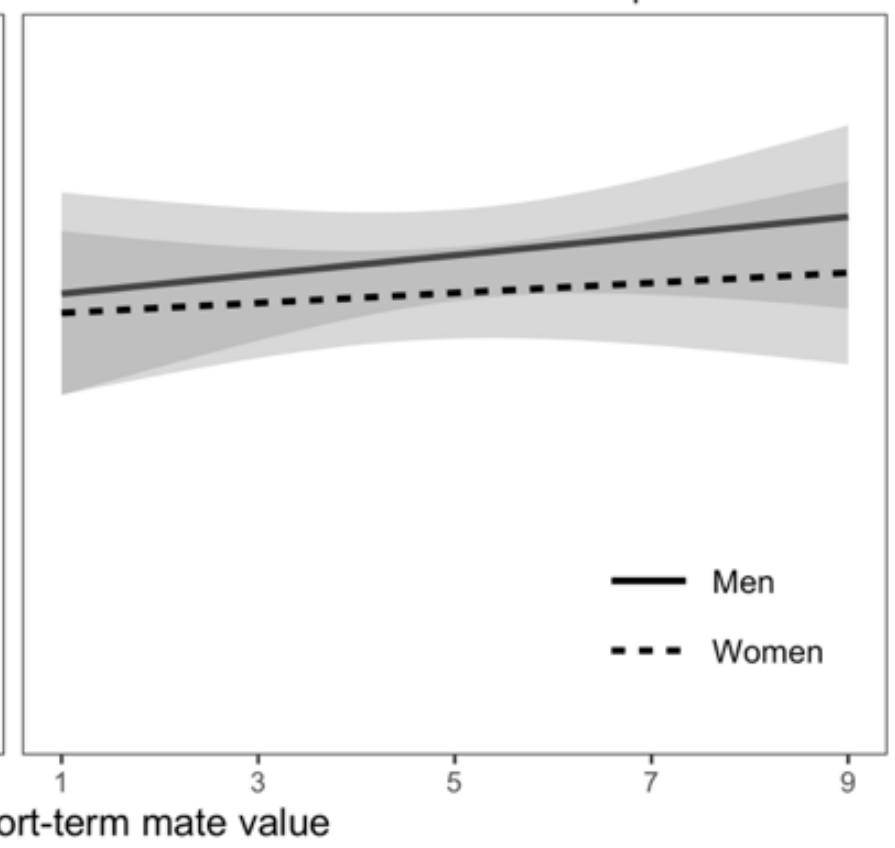

Figure 2

Summary of results from Study 1. Panel A (top): Linear regression estimates of life satisfaction as a function of self-perceived long-term mate value, sex, and relationship status. Panel B (bottom): Linear regression estimates of life satisfaction as a function of self-perceived short-term mate value, sex, and relationship status. Note. Lines denote predicted values and shades denote $95 \%$ confidence intervals (Cls) extracted from the full model. 
A
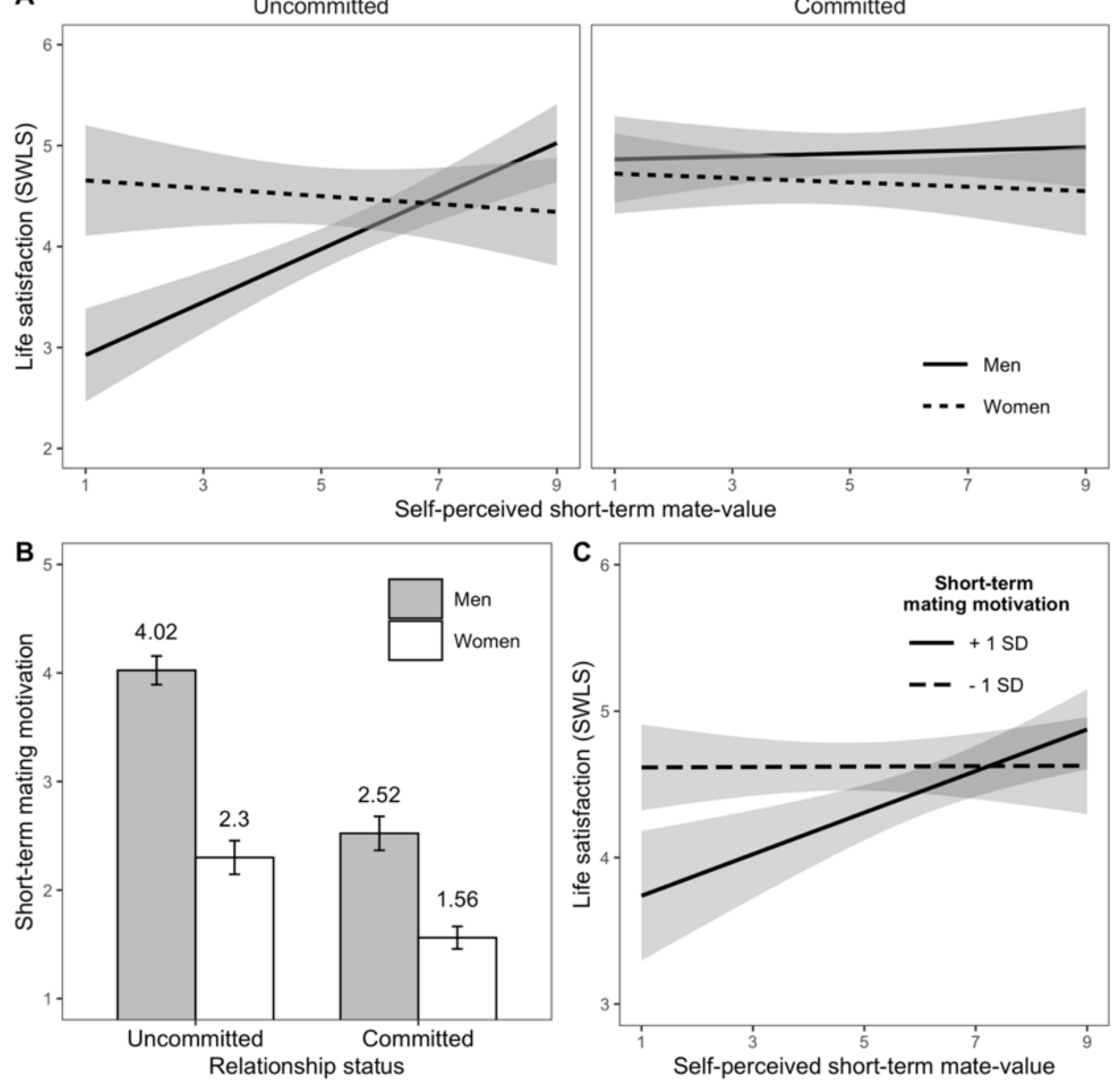

Figure 3

Summary of results from Study 2A. Panel A (top): Linear regression estimates of life satisfaction as a function of self-perceived short-term mate value, sex, and relationship status. Panel B (bottom left): Mean short-term mating motivation as a function of sex and relationship status. Error bars represent $\pm 1 \mathrm{SE}$. Panel C (bottom right): Linear regression estimates of life satisfaction as a function of short-term mate value and short-term mating motivation at 1 SD above and below the mean. 

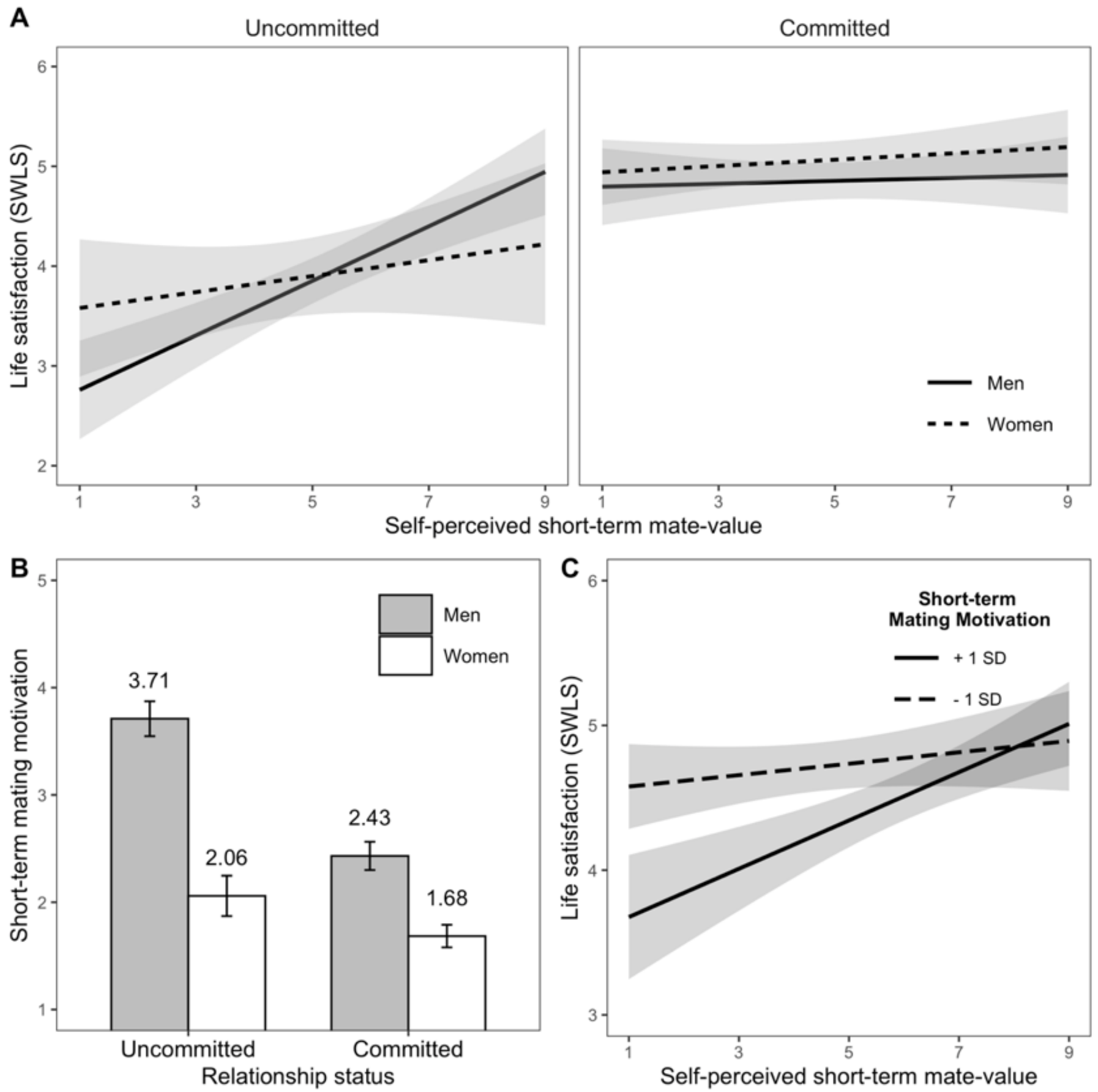

Figure 4

Summary of results from Study 2B. Panel A (top): Linear regression estimates of life satisfaction as a function of self-perceived short-term mate value, sex, and relationship status. Panel B (bottom left): Mean short-term mating motivation as a function of sex and relationship status. Error bars represent $\pm 1 S E$. Panel C (bottom right): Linear regression estimates of life satisfaction as a function of short-term mate value and short-term mating motivation at 1 SD above and below the mean. 


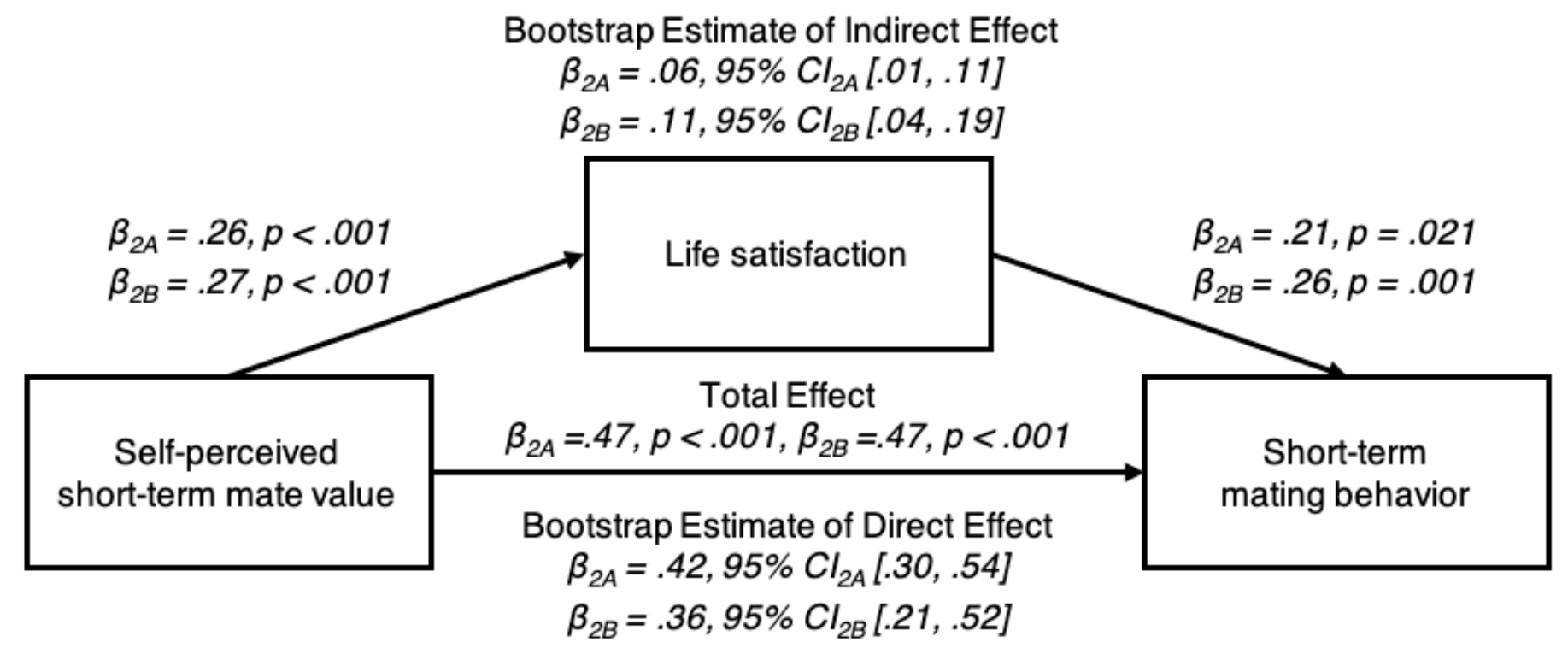

Figure 5

Mediation model from Studies 2A and 2B showing the effect of self-perceived mate-value on short-term mating behavior as partially statistically mediated by life satisfaction for uncommitted men.

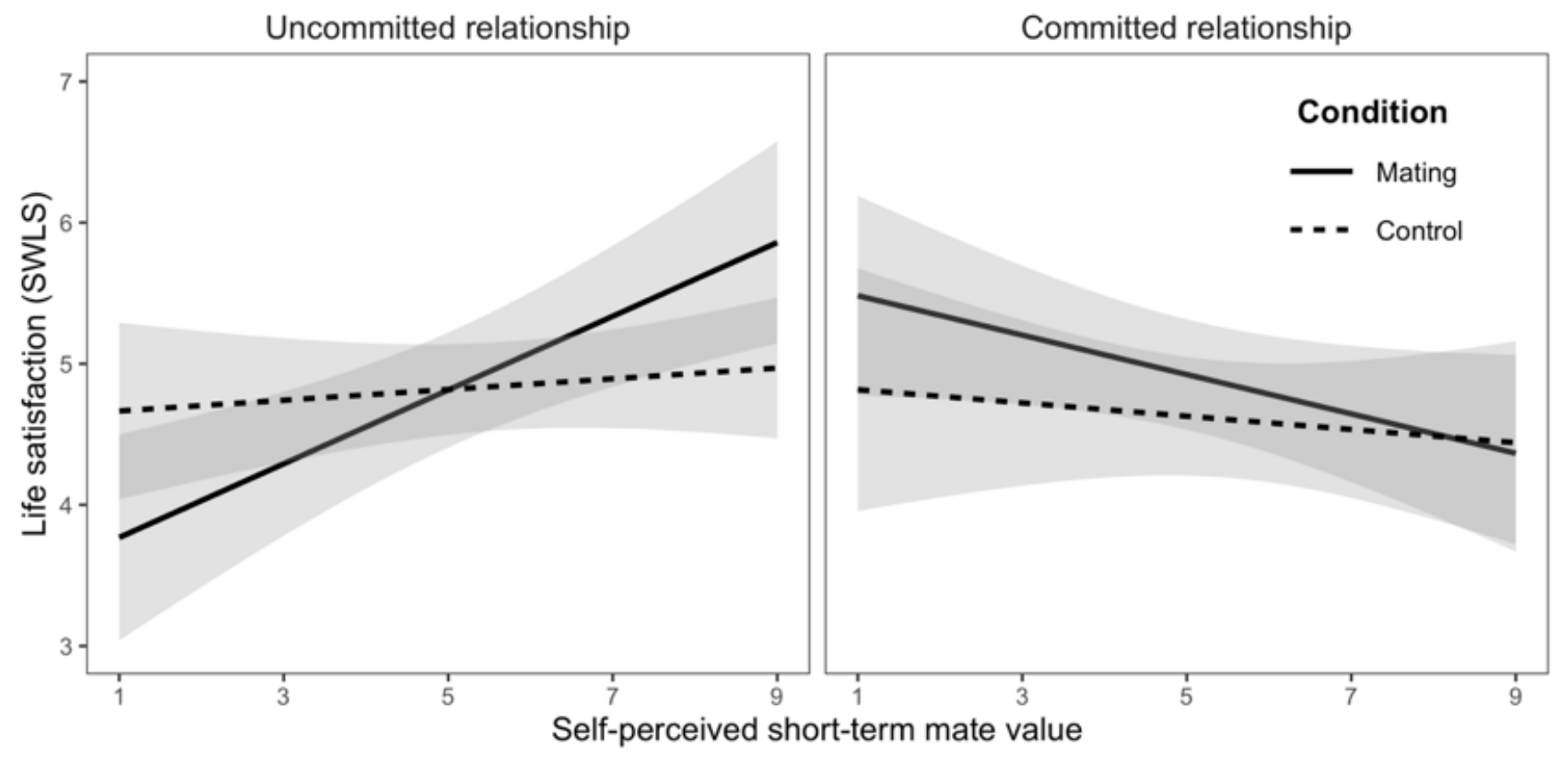

Figure 6

Summary of results from Study 3. Linear regression estimates of women's life satisfaction as a function of self-perceived short-term mate value, priming condition (short-term mating motivation vs. control), and relationship status. 


\section{Supplementary Files}

This is a list of supplementary files associated with this preprint. Click to download.

- FunctionallyCalibratingLifeSatisfactionSupplement.docx 